\title{
Interaction of tumor cells with the microenvironment
}

\author{
Hendrik Ungefroren ${ }^{1 *}$, Susanne Sebens ${ }^{2}$, Daniel Seidl ${ }^{1,3}$, Hendrik Lehnert ${ }^{1}$ and Ralf Hass ${ }^{4}$
}

\begin{abstract}
Recent advances in tumor biology have revealed that a detailed analysis of the complex interactions of tumor cells with their adjacent microenvironment (tumor stroma) is mandatory in order to understand the various mechanisms involved in tumor growth and the development of metastasis. The mutual interactions between tumor cells and cellular and non-cellular components (extracellular matrix = ECM) of the tumor microenvironment will eventually lead to a loss of tissue homeostasis and promote tumor development and progression. Thus, interactions of genetically altered tumor cells and the ECM on the one hand and reactive non-neoplastic cells on the other hand essentially control most aspects of tumorigenesis such as epithelial-mesenchymal-transition (EMT), migration, invasion (i.e. migration through connective tissue), metastasis formation, neovascularisation, apoptosis and chemotherapeutic drug resistance. In this mini-review we will focus on these issues that were recently raised by two review articles in CCS.
\end{abstract}

Keywords: cancer-associated fibroblast, cell migration, epithelial-to mesenchymal transition, extracellular matrix, mammary adenocarcinoma, pancreatic ductal adenocarcinoma, tumor-associated macrophage, tumor stroma, metastasis

\section{Introduction}

The complex process of metastasis formation can be divided into several stages: emigration from the primary tumor, invasion of the surrounding tissue and its extracellular matrix (ECM), intravasation into the circulation or the lymphatic system via transmigration through the endothelial lining and the basement membrane, and finally extravasation and metastasis formation at target sites. During each stage, tumor cells have to detach, migrate, invade, adapt and re-attach by involving matrix degrading enzymes and mechanical processes such as cell adhesion, changes of cell fate, cell movements and motility, and the generation of forces. Indeed, an understanding of the invasion process is only possible in the context of detailed insights into the cancer cell's interactions with the microenvironment. These interactions are determined by structural and biochemical properties of the ECM as well as by communication with surrounding non-neoplastic cells such as endothelial cells (ECs,

\footnotetext{
* Correspondence: hendrik.ungefroren@uk-sh.de

${ }^{1}$ First Department of Medicine, University Hospital Schleswig-Holstein,

Campus Lübeck, Ratzeburger Allee 160, 23538 Lübeck, Germany

Full list of author information is available at the end of the article
}

during the process of transendothelial migration), cancer-associated fibroblasts (CAFs), mesenchymal stem cells (MSC), and a variety of different immune cells including lymphocytes and tumor-associated macrophages (TAMs). Since these multiple interactions with the tumor stroma determine not only cancer growth and metastasis but may also develop protective effects with respect to the tumor cells' drug sensitivity/resistance, the tumor stroma also has to be considered as a potential therapeutic target. Specifically, a deeper understanding of these interactions will elucidate the mechanisms of action of classical drugs that have been discovered by empirical approaches and, even more appealing, will facilitate the design and development of novel mechanistically-acting or even individuallydesigned drugs. This particularly applies for tumors exhibiting a pronounced stromal compartment such as invasive mammary adenocarcinoma $(\mathrm{MaCa})$ and the highly malignant pancreatic ductal adenocarcinoma (PDAC), the latter still presenting as largely resistant to current drug-based therapies. In this mini-review, we refer to two articles which recently appeared in this journal $[1,2]$ describing the major types of tumor stroma

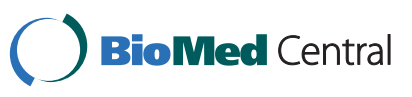


interactions (cancer cell with non-neoplastic cells and cancer cell with ECM). The issues raised in these articles will be discussed here in a wider context, including the current view on the role of the tumor stroma in metastasis formation. Special attention is devoted to the dialogue of tumor cells with TAMs, CAFs, and ECs and the role of transforming growth factor (TGF) $\beta$ in the regulation of cancer cell migration and invasion. We extend the data presented by Brabek et al. [1] and Calorini \& Bianchini [2] by highlighting those interactions that are already exploited, or are potentially suitable for targeted therapeutic intervention.

\section{Cancer cell interactions with the ECM}

Matrix invasion is a crucial prerequisite for metastasis and has to be regarded largely as a mechanical process dependent on the expression of adhesion molecules and matrix degrading enzymes. As outlined by Brabek et al. [1], the architecture and composition of the microenvironment in terms of structural and biochemical properties of the ECM (fiber network morphology collagen content, fiber thickness, extent of intrafibrillar crosslinks, and the ratio mesh size-diameter of the migrating cell) determines the degree of resistance the moving cell encounters. This in turn will determine the migration strategy and efficiency of cancer cell invasion. Tumor cells are capable of mechanosensing the composition of the ECM which is facilitated by integrin-mediated adhesions and downstream mechanosensor proteins such as focal adhesion kinase $\left(\mathrm{p} 125^{\mathrm{FAK}}\right)$. On the one hand, increased "stiffness" evokes focal adhesions and increases RhoA-mediated actomyosin contraction. Thus, tissue rigidity can potently stimulate directed cell migration [3]. On the other hand, the mechanical properties of the ECM can be remodeled by tumor cells leading to characteristic stiffening of the tumor tissue through collagen crosslinking and increased focal adhesion formation in breast cancer [4]. In addition, contact guidance which is the aligning behavior mediated by mechanosensory integrins also determines the migratory behavior of the tumor cells. Inhibition of integrin signaling represses invasion and hence integrins and their downstream mediators represent viable therapeutic targets for anticancer treatment. In fact, targeting of several integrins, particularly $\beta 1$ integrin [5] is currently evaluated in preclinical or clinical studies in various tumor types including $\alpha v \beta 3$ (Vitaxin, MEDI-522), $\alpha v \beta 3$ and $\alpha v \beta 5$ (Cilengitide, EMD 121974), $\alpha \mathrm{v}$ integrins (CNTO 95), $\alpha 5 \beta 1-\mathrm{I}$ and $\alpha \mathrm{v} \beta 3$ (ATN-161), $\alpha 2$ integrin subunit (E7820) and $\alpha 5 \beta 1$ integrin (Volociximab, Eos-200-4, M200) [reviewed in Ref. [6]]. Reduction of lysyl oxidase (LOX), a copper-dependent amine oxidase that catalyses the crosslinking of collagens, elastin, and fibrillin in the ECM [7] reduces matrix stiffening and thereby impedes malignancy and affects tumor development in $\mathrm{MaCa}$ [4]. Furthermore, hydrogen peroxide which is generated as a metabolic product of LOX activity, stimulates activity of the small GTPase Rac1 [8] and thereby enhances the migratory/invasive behavior of tumor cells [9]. However, although LOX appears to represent a promising molecular target [10], LOX inhibitors have not yet been validated in clinical settings.

Cancer cells utilize different strategies for migration, namely collective versus individual movement [11]. During collective movements the tumor cells retain their intracellular junctions [11] while individual migration strategies can be performed either mesenchymal-like or amoeboid. Both strategies are interchangeable with bidirectional transition and differentially controlled by growth factors. Conversion of epithelial cells to individually migrating mesenchymal cells is achieved by a process called epithelial-mesenchymal-transition (EMT). EMT can be induced by several stimuli, e.g. TGF- $\beta 1$ and is regarded as a prerequisite for mesenchymal cancer cell migration and invasion in breast and pancreatic cancer [reviewed in Refs. [12,13]]. This concept has recently raised great attention since besides its role in conveying the ability for individual migration upon tumor cells it also contributes to drug resistance [14], escape from oncogene-induced premature senescence [15], acquisition of stem cell features [16], and resistance to anoikis [17] in various tumors. TGF- $\beta$ promotes EMT and single cell motility, which enables invasion into blood vessels, while in the absence of TGF- $\beta$, cells are restricted to collective movement and lymphatic spread [18]. For mesenchymal invasion, cells adopt a spindle-like shape with pseudopodia, whereas the amoeboid invasion mode is characterized by cycles of expansion and contraction of the cell body and bleb-like protrusions. The amoeboid migration mode has been described in leukocytes and many types of tumor cells which requires little or no receptor-facilitated adhesion to the ECM. Since this process is protease-independent it may be less susceptible to both integrin and matrix metalloprotease (MMP) inhibitors. Indeed, the failure of MMP inhibitors in recent clinical trials to prevent cancer progression points to the possibility that protease-independent mechanisms of invasion may be clinically relevant. For instance, tumor cells may undergo a mesenchymal-to-amoeboid transition after blocking pericellular proteolysis or integrins. Since the spatial organisation of collagen and elastin fibers can determine the mode of invasion, i.e. whether the cells move amoeboid-like, protease-independent, or mesenchymal, it may be appealing to first alter the stiffness of the ECM by treatment with LOX-inhibitors (see above) in order to force cancer cells to adopt a particular mode of invasion and subsequently apply inhibitors that specifically target this invasion mode. 


\section{Cancer cell interactions with non-neoplastic cells}

Besides the ECM, non-neoplastic cells in the tumor microenvironment strongly impact on tumor cell migratory and invasive properties. Supporting this idea, the review by Calorini and Biancini [2] critically addresses experimental evidence that macrophages, fibroblasts, ECs, and other types of stromal cells that are not discussed in this article (e.g. MSC) control and alter the tumoral microenvironment by inducing changes facilitating the tumor cells' local and distant dissemination. Moreover, these non-neoplastic cells can change their phenotype upon soluble or physical contact-mediated stimulation by tumor cells towards a tumor-promoting one.

TAMs derived from differentiated monocytes that have been recruited to the reactive stroma in response to tumoral chemotactic factors, or from resident macrophages, represent the major component of the immune infiltrate in $\mathrm{MaCa}$ and PDAC $[19,20]$. There are two major lines connecting macrophages and cancer: i) accumulation of macrophages in tissues of chronic inflammation apparently promotes cancer initiation and progression and ii) a high density of TAMs in tumor tissues often correlates with poor prognosis for cancer patients [21]. Since macrophages are generally important for $\mathrm{T}$ cell activation and the initiation of $\mathrm{T}$ cell-mediated immune responses, it is not clear whether the opposing effects exerted by TAMs on tumor growth and metastasis development reflect different states of activation acquired by TAMs in the tumor microenvironment or whether multiple subpopulations of TAMs exist within the tumor [22]. Experimental evidence indicates that depending on the stimuli, monocytes can differentiate into pro-inflammatory (M1-) or anti-inflammatory (M2-, alternatively activated) macrophages. TAMs resemble M2 macrophages and are generally thought to promote tumor progression because of their inability to induce $\mathrm{T}$ cell activation along with their elevated expression of scavenger and mannose receptors and the release of pro-tumorigenic factors such as TGF- $\beta 1$, IL-10, proangiogenic factors and MMPs [23]. Moreover, elevated levels of IL- 10 and TGF- $\beta 1$ found in the tumoral microenvironment of many tumors such as $\mathrm{MaCa}$ and PDAC are believed to mediate a conversion from M1 to M2 macrophages [24].

It is well accepted that TAMs are required for tumor cell migration, invasion, and metastasis formation [25-27]. Altogether, tumor cells exposed to TAMs' prometastatic activity exhibit increased invasiveness and an enhanced capacity to adhere to ECs and thus eventually (and indirectly) facilitate transendothelial migration. Along the same line are observations that tumor cell intravasation (at least in mammary tumors) occurs in association with perivascular macrophages [28].
However, the best characterized pro-tumoral function of TAMs relates to their pro-angiogenic capacities. TAMs generally accumulate in hypoxic areas of the tumor and hypoxia in turn triggers a pro-angiogenic program in these cells. Thereby, TAMs promote the angiogenic switch and neovascularization as well as malignant transition of the tumor cells by secretion of specific proangiogenic factors (VEGF, IL- $1 \beta$, TNF- $\alpha$, angiogenin, semaphorin 4D), or indirectly through the release of MMP-9. Accordingly, tumor cells co-cultured with macrophages display increased cell migration which is mediated through TNF- $\alpha$ which is released by macrophages [29]. MMPs which are important for ECM degradation and tumor cell invasion through connective tissue can be released by both tumor cells and TAMs. Thus, tumor cells may stimulate TAMs to produce MMPs in a paracrine manner through secretion of interleukins and growth factors. It is also possible that MMPs secreted by TAMs can be recruited to cancer cell membranes and used there by the tumor cells to progress through a specific site. Paracrine stimulation of macrophage-derived MMPs is expected to stimulate protease-dependent modes of cancer cell invasion which are likely susceptible to MMP inhibitors. Another mode of interaction is represented by a GM-CSF/HB-EGF paracrine loop that is utilised by macrophages to promote cancer growth [30] and may be successfully targeted with EGF receptor inhibitors. Indeed, during aging-associated breast cancer development a contribution of signalling events between MMP-7 and HB-EGF has been discussed. Thus, in young normal human mammary epithelial cells (HMEC), MMP-7 can bind to several glycosylation branches of the CD44 receptor isoform variant-3 (CD44v3) which can colocalize with MMP-7 and anchor this proteinase to the cell surface in close vicinity to membrane-bound pro-HB-EGF $[31,32]$. This reveals a close interaction between MMP-7 and HB-EGF which is not detectable in aging HMEC [32]. Consequently, an extracellular cleavage of proHB-EGF by MMP-7 enhances the availability of soluble HB-EGF (sHB-EGF) which can bind to and interact with the ErbB4 receptor $[33,34]$. This process can be observed in normal young proliferating HMEC [32]. Conversely, altered expression levels of sHB-EGF and the ErbB4 receptor have been reported in neoplastic breast cancer cells $[32,35]$. In association with these proliferation signals, previous work has also suggested that MMP-7 can mediate neoplastic growth of mammary epithelial cells via the ErbB4 receptor [34]. The signals relayed by HBEGF via the ErbB4 receptor involve the mitogen-activated protein kinase (MAPK) pathway and can also be identified in normal and neoplastic breast tissue to mediate an increased proliferation signal [36]. Moreover, adjacent TAMs, CAFs, and MSC within the neoplastic 
tissue microenvironment contribute to the release of growth factors (Figure 1). Particularly MSC which represent different subpopulations [37] and alter metabolic activities in an hypoxic microenvironment [38] can further enhance the proliferative capacity during maturation and interact with tumor cell populations [39]. In addition, co-culture experiments revealed that senescent human fibroblasts can affect neighboring epithelial cells, for example by increasing the survival and growth of pre-malignant and malignant mammary epithelial cells or by altering the functional differentiation and branching morphogenesis of normal breast epithelial cells $[40,41]$. Upon appropriate signals from the tumor cells, TAMs also produce and activate other extracellular matrix proteases including the urokinasetype plasminogen activator ( $\mathrm{UPA}$ ) and its receptor, uPAR, that may cause ECM degradation to promote invasion and spreading of tumor cells [42]. The expression of UPAR has been shown to be fairly high in tumor compared to normal, quiescent tissues, which has led to uPAR being proposed as a therapeutic target, as well as a targeting agent, for the treatment of cancer [43].

Another important non-neoplastic cell type found in the tumor stroma is the CAF. CAFs actively contribute to tumor progression [44], like tumor cells are capable of monocyte recruitment, and like TAMs promote

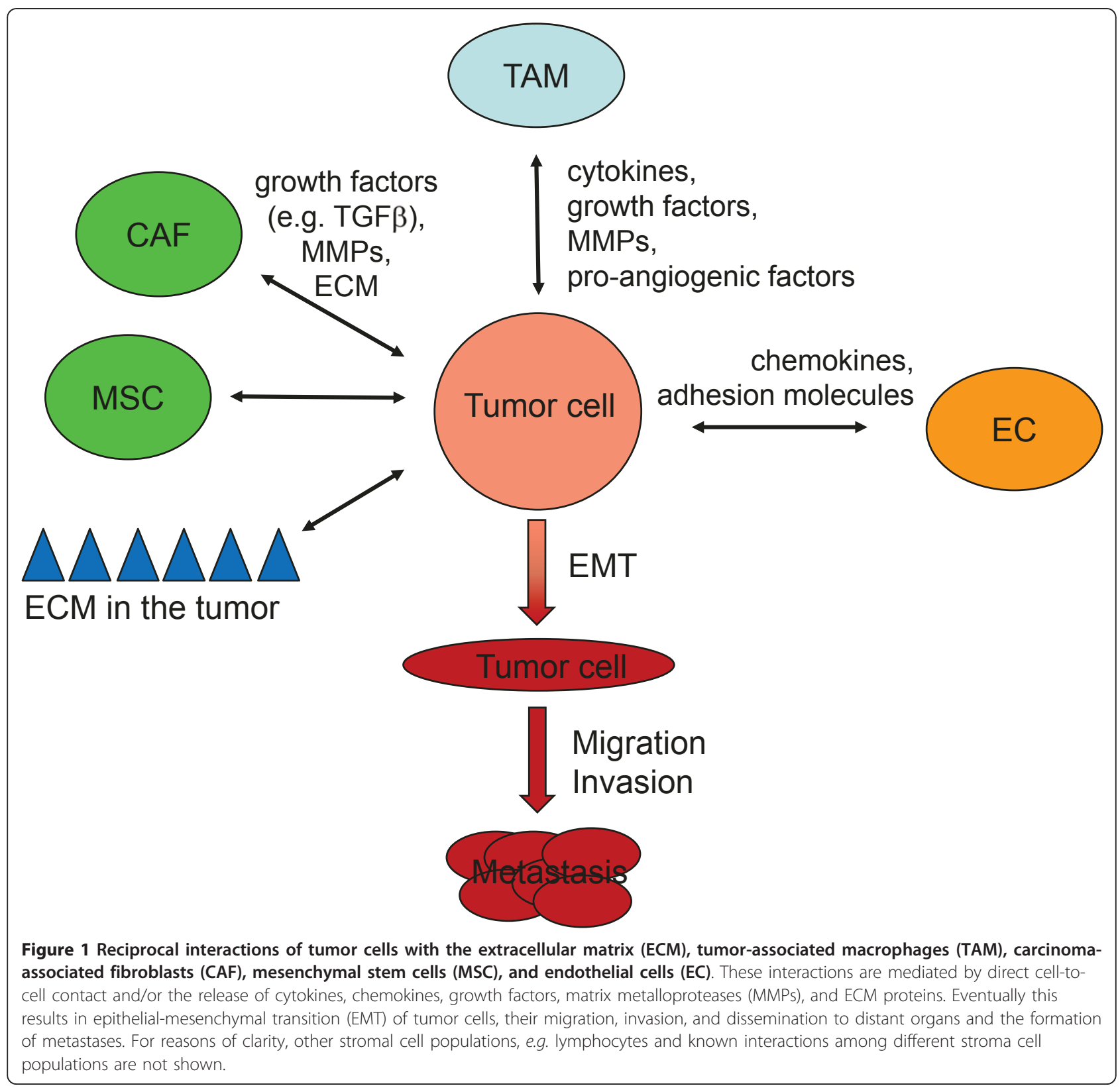


neovascularization, cancer cell proliferation, survival, and invasion (Figure 1). In addition, CAFs can be generated as activated fibroblasts or myofibroblasts from normal fibroblasts by stimulation with TGF- $\beta 1$. Tumor cellderived TGF- $\beta$ stimulates reactive oxygen species (ROS)-dependent expression of $\alpha$-smooth muscle actin in the fibroblasts leading to their differentiation into myofibroblasts [45], offering the theoretical possibility of therapeutically preventing this conversion with ROS scavengers like $\mathrm{N}$-acetyl-cysteine. In this activated state, CAFs produce a variety of cytokines, growth factors and ECM proteins by which they alter both the tumor cells and the stromal microenvironment and promote tumor progression. For instance, CAF-derived hepatocyte growth factor leads to an invasive phenotype and, like TGF- $\beta$, can induce EMT in tumor cells. As a consequence, the EMT associated transcription factors Twist1 and 2 may override oncogene-induced premature senescence in cancer cells [16], providing a link between early escape from failsafe programs/prevention of oncogeneinduced senescence and the acquisition of invasive features by cancer cells.

By producing ECM proteins, CAFs can determine the biophysical properties of the ECM (thereby indirectly influence cancer cell motility and invasion modes) and act as barrier against tumor-infiltrating immune cells and access of anti-cancer drugs to the tumor cells [46], facilitate cell contacts and motility, and stimulate secreted proteins which in turn stimulate invasiveness, angiogenesis and tissue remodeling. CAF-secreted metalloproteases, such as MMP-3, elicit a Rac1b (a tumor-specific splice variant of Rac1)/COX-2-mediated release of ROS in carcinoma cells which is mandatory for EMT, stemness, and dissemination of metastatic cells [47]. Inhibitors of MMPs, small GTPases, and ROS may thus cross-target CAF-mediated prooncogenic events. Moreover, CAFs from invasive human breast carcinomas promote tumor growth and neoangiogenesis through a SDF-1/CXCR4-dependent recruitment of endothelial progenitor cells [48].

Besides interactions with TAMs and CAFs, the interplay of tumor cells with ECs is also of pivotal importance for tumor progression and the development of metastasis. It is generally assumed that cancer cell migration through connective tissue is too slow and undirected to account for the quick spreading and metastasis formation seen in many tumors, and that cancer cells spread much more quickly and efficiently via lymph or blood vessels to distant sites. The endothelium and the basement membrane constitute a strong physical barrier, hence the process of intravasation is potentially time-consuming and rate-limiting in metastasis development. The mechanisms by which cancer cells can transmigrate through the endothelial lining are not well understood. Signaling cross-talk between cancer cells and ECs may involve upregulation of adhesion molecule expression by the endothelium as well as by the tumor cells, reorganisation of the acto-myosin cytoskeleton, and Src-mediated disruption of endothelial VEcadherin- $\beta$-catenin cell-cell adhesions. Paracellular transmigration through the formation of holes within the monolayer and through induction of EC apoptosis is currently discussed. Similar mechanisms may also operate in the generation of pleural effusions often seen in breast cancer patients or ascites in patients with PDAC [49]. As mentioned above, tumor cell intravasation can occur in association with perivascular macrophages [29] enriched for molecules of the Wnt signaling pathway [50]. Signals from cancer cells (and possibly perivascular macrophages), e.g. production of inflammatory cytokines such as TNF- $\alpha$, and IL- $1 \beta$ promote transmigration and invasion by several mechanisms while signals from ECs like chemokines (GRO- $\beta$, IL-8) lead to enhanced contractile force generation and cytoskeletal remodeling. A better understanding of cancer cell transmigration may provide multiple potential targets for therapeutic intervention.

\section{TGF- $\beta$ : a growth factor of pivotal importance for cancer cell migration/invasion and metastasis formation}

The importance of TGF- $\beta$ signaling for progression of invasive $\mathrm{MaCa}$ and PDAC is well documented [51,52]. Recently, the TGF- $\beta$ pathway has been identified as one of only 4 signaling pathways with $100 \%$ alteration in PDAC [53]. As outlined above, TGF- $\beta$ can directly regulate cell migration and invasion during later stages of tumor progression by promoting EMT and single cell motility. To induce this pro-migratory function, TGF- $\beta$ may exploit signaling crosstalk with other oncogenes and small GTPases with known roles in cellular adhesion, migration, and invasion such as Src [54], K-ras [55], and Rac1 [56]. Moreover, TGF- $\beta$ is involved in many aspects in the dialogue of cancer cells with the non-neoplastic cells of the tumor microenvironment, particularly the generation/conversion of TAMs and CAFs from monocytes and fibroblasts, respectively, and the induction of adhesion molecule expression in neighboring normal cells [57]. However, TGF- $\beta$ signaling mediated by CAFs can suppress tumor formation and progression in adjacent epithelia [58]. In addition, TGF$\beta$ may also directly regulate ECM tension and stiffness (through increasing the expression of ECM proteins by tumor cells or CAFs and/or the function of LOX,) and thereby increasing the oncogenic activities (e.g. proliferation) of cancer cells. In mammary carcinoma, TGF- $\beta$ appears to play a key role in maintaining the mammary epithelial (cancer) stem cell pool, in part by inducing a mesenchymal phenotype, while differentiated, estrogen 
receptor-positive, luminal cells are unresponsive to TGF- $\beta$ because the TGFBR2 receptor gene is transcriptionally silent [59].

In human carcinoma, tumor-cell-autonomous expression of TGF- $\beta$ is often increased, whereas expression of the receptor-dependent signaling components is decreased, mutated, or silenced. TGF- $\beta$ is an early tumor suppressor that can subsequently promote tumor progression through tumor-cell-autonomous and tumorstroma interactions resulting in metastasis development, immune evasion, and the stimulation of angiogenesis [58]. This suggests that therapeutic targeting of TGF- $\beta$ signaling in cancer cells and TAMs is a feasible therapeutic option. TGF- $\beta$ pathway inhibitors including small and large molecules have now entered clinical trials. Preclinical studies with these inhibitors have shown promise in a variety of different tumor models [60]. More recently, we have discovered that the common Src family kinase inhibitors PP1 and PP2 are powerful inhibitors in vitro of T $\beta R I$ and II [61]. If this also applies to their action in vivo they may have the advantage of dually inhibiting oncogenic Src and TGF- $\beta$ signaling and are likely to be much more effective in the treatment of late-stage $\mathrm{MaCa}$ and PDAC than agents with single specificity.

\section{Conclusions}

The tumor stroma provides unique structural features that significantly differ from those of the respective normal tissue. On the one hand cancer cells respond to this environment through modulation of cell adhesion/ migration molecules (e.g. L1-CAM, integrins), contact guidance, cytoskeletal reorganisation, cell shape changes, as well as secretion of proteolytic enzymes (MMP-7/-9), growth factors (HB-EGF), chemokines, and cytokines (TNF $\alpha, T G F-\beta s$ ). On the other hand, tumor cell-derived signals recruit and activate host cells among which monocytes/TAMs, fibroblasts/CAFs and MSC are the most abundant populations within the tumor microenvironment. Thus, the dynamic and reciprocal interactions between tumor cells and cells of the tumor microenvironment as well as the ECM orchestrate events critical to tumor progression and metastasis formation.

Current efforts are directed towards studying these various types of tumor cell-stromal cell and tumor cellmatrix interactions in diverse experimental settings. Intense investigations in this field have revealed that the mechanisms that allow CAFs and TAMs or the ECM to contribute to tumor progression also determine the sensitivity of tumor cells towards chemotherapeutic drugs. Drug resistance, intrinsic or acquired, essentially limits the efficiency of chemotherapy in many cancer patients and is the result of reduced accessibility or accumulation of a drug in the tumor tissue (e.g. as a consequence of increased matrix deposition acting as a physical barrier), but also of protection from induction and execution of apoptosis in cancer cells. Thus, by interacting with the ECM and/or stroma cells, tumor cells become highly protected from apoptosis induction involving alterations in the expression of adhesion molecules such as L1CAM or integrins, or elevated secretion of cytokines (TGF- $\beta$ ) and chemokines. Since many of these molecules and their signaling intermediates are involved in the control of cell migration and invasion, cell survival, and apoptosis at the same time, they represent particularly exciting molecular targets for anti-cancer therapy.

\section{Abbreviations}

CAFs: cancer-associated fibroblasts; ECs: endothelial cells; ECM: extracellular matrix; EMT: epithelial-mesenchymal transition; LOX: lysyl oxidase; MaCa: mammary carcinoma; MSC: mesenchymal stem cell; MMP: matrix metalloprotease; PDAC: pancreatic ductal adenocarcinoma; ROS: reactive oxygen species; TAMs: tumor-associated macrophages; TGF- $\beta$ : transforming growth factor-beta; uPA: urokinase-type plasminogen activator.

\section{Author details}

${ }^{1}$ First Department of Medicine, University Hospital Schleswig-Holstein, Campus Lübeck, Ratzeburger Allee 160, 23538 Lübeck, Germany. ${ }^{2}$ Institute for Experimental Medicine c/o Department of Internal Medicine I, University Hospital Schleswig-Holstein, Campus Kiel, Arnold-Heller-Strasse 3, Haus 6, 24105 Kiel, Germany. ${ }^{3}$ Department of Radiation Oncology, University Hospital Schleswig-Holstein, Campus Lübeck, Ratzeburger Allee 160, 23538 Lübeck, Germany. ${ }^{4}$ Laboratory of Biochemistry and Tumor Biology, Department of Obstetrics and Gynecology, Medical University, Hannover, Carl-NeubergStrasse 1, 30625 Hannover, Germany.

\section{Authors' contributions}

$\mathrm{HU}, \mathrm{SS}$, and RH wrote the manuscript. DS and HL were involved in the conceptualization and discussion of the manuscript. All authors read and approved the final version of the manuscript.

\section{Competing interests}

The authors declare that they have no competing interests.

Received: 27 July 2011 Accepted: 13 September 2011

Published: 13 September 2011

\section{References}

1. Brábek J, Mierke $C T$, Rösel $D$, Veselý P, Fabry B: The role of the tissue microenvironment in the regulation of cancer cell motility and invasion. Cell Commun Signal 2010, 8:22.

2. Calorini L, Bianchini F: Environmental control of invasiveness and metastatic dissemination of tumor cells: the role of tumor cell-host cell interactions. Cell Commun Signal 2010, 8:24.

3. Butcher DT, Alliston T, Weaver VM: A tense situation: forcing tumour progression. Nat Rev Cancer 2009, 9:108-122.

4. Levental KR, Yu H, Kass L, Lakins JN, Egeblad M, Erler JT, Fong SF, Csiszar K, Giaccia A, Weninger W, et al: Matrix crosslinking forces tumor progression by enhancing integrin signaling. Cell 2009, 139:891-906.

5. Cordes N, Park CC: beta1 integrin as a molecular therapeutic target. Int J Radiat Biol 2007, 83:753-760.

6. Tucker GC: Integrins: Molecular targets in cancer therapy. Curr Oncol Rep 2006, 8:96-103.

7. Payne SL, Fogelgren B, Hess AR, Seftor EA, Wiley EL, Fong SF, Csiszar K, Hendrix MJ, Kirschmann DA: Lysyl oxidase regulates breast cancer cell migration and adhesion through a hydrogen peroxide-mediated mechanism. Cancer Res 2005, 65:11429-11436. 
8. Radisky DC, Levy DD, Littlepage LE, Liu H, Nelson CM, Fata JE, Leake D, Godden EL, Albertson DG, Nieto MA, et al: Rac1b and reactive oxygen species mediate MMP-3-induced EMT and genomic instability. Nature 2005, 436:123-127.

9. Erler JT, Giaccia AJ: Lysyl oxidase mediates hypoxic control of metastasis. Cancer Res 2006, 66:10238-10241.

10. Rodríguez C, Rodríguez-Sinovas A, Martínez-González J: Lysyl oxidase as a potential therapeutic target. Drug News Perspect 2008, 21:218-224.

11. Friedl P, Gilmour D: Collective cell migration in morphogenesis, regeneration and cancer. Nat Rev Mol Cell Biol 2009, 10:445-457.

12. Takebe N, Warren RQ, Ivy SP: Breast cancer growth and metastasis: interplay between cancer stem cells, embryonic signaling pathways and epithelial-to-mesenchymal transition. Breast Cancer Res 2011, 13:211.

13. Hotz HG, Hotz B, Buhr HJ: Genes associated with epithelial-mesenchymal transition: possible therapeutic targets in ductal pancreatic adenocarcinoma? Anticancer Agents Med Chem 2011, 11:448-454.

14. Arumugam $T$, Ramachandran V, Fournier KF, Wang $H$, Marquis $L$, Abbruzzese JL, Gallick GE, Logsdon CD, McConkey DJ, Choi W: Epithelial to mesenchymal transition contributes to drug resistance in pancreatic cancer. Cancer Res 2009, 69:5820-5828.

15. Ansieau S, Bastid J, Doreau A, Morel AP, Bouchet BP, Thomas C, Fauvet F, Puisieux I, Doglioni C, Piccinin S, et al: Induction of EMT by twist proteins as a collateral effect of tumor-promoting inactivation of premature senescence. Cancer Cell 2008, 14:79-89.

16. May CD, Sphyris N, Evans KW, Werden SJ, Guo W, Mani SA: Epithelialmesenchymal transition and cancer stem cells: a dangerously dynamic duo in breast cancer progression. Breast Cancer Res 2011, 13:202.

17. Klymkowsky MW, Savagner P: Epithelial-mesenchymal transition: a cancer researcher's conceptual friend and foe. Am J Pathol 2009, 174:1588-1593.

18. Giampieri S, Pinner S, Sahai E: Intravital imaging illuminates transforming growth factor beta signaling switches during metastasis. Cancer Res 2010, 70:3435-3439.

19. Tsutsui S, Yasuda K, Suzuki K, Tahara K, Higashi H, Era S: Macrophage infiltration and its prognostic implications in breast cancer: the relationship with VEGF expression and microvessel density. Oncol Rep 2005, 14:425-431.

20. Kurahara H, Shinchi H, Mataki Y, Maemura K, Noma H, Kubo F, Sakoda M, Ueno S, Natsugoe S, Takao S: Significance of M2-polarized tumorassociated macrophage in pancreatic cancer. J Surg Res 2011, 167 e211-219.

21. Leek RD, Lewis CE, Whitehouse R, Greenall M, Clarke J, Harris AL: Association of macrophage infiltration with angiogenesis and prognosis in invasive breast carcinoma. Cancer Res 1996, 56:4625-4629.

22. Stout RD, Watkins SK, Suttles J: Functional plasticity of macrophages: in situ reprogramming of tumor-associated macrophages. J Leukoc Biol 2009, 86:1105-1109.

23. Sica A, Larghi P, Mancino A, Rubino L, Porta C, Totaro MG, Rimoldi M, Biswas SK, Allavena P, Mantovani A: Macrophage polarization in tumour progression. Sem Cancer Biol 2008, 18:349-355.

24. Martinez FO, Sica A, Mantovani A, Locati M: Macrophage activation and polarization. Front Biosci 2008, 13:453-461.

25. Allavena P, Sica A, Garlanda C, Mantovani A: The Yin-Yang of tumorassociated macrophages in neoplastic progression and immune surveillance. Immunol Rev 2008, 222:155-161.

26. Condeelis J, Pollard JW: Macrophages: obligate partners for tumor cell migration, invasion, and metastasis. Cell 2006, 124:263-266.

27. Qian BZ, Pollard JW: Macrophage diversity enhances tumor progression and metastasis. Cell 2010, 141:39-51.

28. Wyckoff JB, Wang Y, Lin EY, Li JF, Goswami S, Stanley ER, Segall JE, Pollard JW, Condeelis J: Direct visualization of macrophage-assisted tumor cell intravasation in mammary tumors. Cancer Res 2007, 67:2649-2656.

29. Coffelt SB, Hughes R, Lewis CE: Tumor-associated macrophages: effectors of angiogenesis and tumor progression. Biochim Biophys Acta 2009, 1796:11-18.

30. Rigo A, Gottardi M, Zamò A, Mauri P, Bonifacio M, Krampera M, Damiani E, Pizzolo G, Vinante F: Macrophages may promote cancer growth via a GM-CSF/HB-EGF paracrine loop that is enhanced by CXCL12. Mol Cancer 2010, 9:273.

31. Yu WH, Woessner JF Jr, McNeish JD, Stamenkovic I: CD44 anchors the assembly of matrilysin/MMP-7 with heparin-binding epidermal growth factor precursor and ErbB4 and regulates female reproductive organ remodeling. Genes Dev 2002, 16:307-323.

32. Bertram C, Hass R: Cellular senescence of human mammary epithelial cells (HMEC) is associated with an altered MMP-7/HB-EGF signaling and increased formation of elastin-like structures. Mech Ageing Dev 2009, 130:657-669.

33. Blaine SA, Ray KC, Branch KM, Robinson PS, Whitehead RH, Means AL: Epidermal growth factor receptor regulates pancreatic fibrosis. Am J Physiol Gastrointest Liver Physiol 2009, 297:G434-441.

34. Lynch CC, Vargo-Gogola T, Martin MD, Fingleton B, Crawford HC, Matrisian LM: Matrix metalloproteinase 7 mediates mammary epithelial cell tumorigenesis through the ErbB4 receptor. Cancer Res 2007, 67:6760-6767.

35. McIntyre E, Blackburn E, Brown PJ, Johnson CG, Gullick WJ: The complete family of epidermal growth factor receptors and their ligands are coordinately expressed in breast cancer. Breast Cancer Res Treat 2010, 122:105-110

36. Lu X, Wang Q, Hu G, Van Poznak C, Fleisher M, Reiss M, Massague Kang Y: ADAMTS1 and MMP1 proteolytically engage EGF-like ligands in an osteolytic signaling cascade for bone metastasis. Genes Dev 2009, 23:1882-1894

37. Majore I, Moretti P, Hass R, Kasper C: Identification of subpopulations in mesenchymal stem cell-like cultures from human umbilical cord. Cell Commun Signal 2009, 7:6.

38. Lavrentieva A, Majore I, Kasper C, Hass R: Effects of hypoxic culture conditions on umbilical cord-derived human mesenchymal stem cells. Cell Commun Signal 8:18.

39. Chaturvedi S, Hass R: Extracellular signals in young and aging breast epithelial cells and possible connections to age-associated breast cancer development. Mech Aging Dev 2011, 132:213-219.

40. Kuperwasser C, Chavarria T, Wu M, Magrane G, Gray JW, Carey L, Richardson A, Weinberg RA: Reconstruction of functionally normal and malignant human breast tissues in mice. Proc Natl Acad Sci USA 2004, 101:4966-4971.

41. Parrinello S, Coppe JP, Krtolica A, Campisi J: Stromal-epithelial interactions in aging and cancer: senescent fibroblasts alter epithelial cell differentiation. J Cell Sci 2005, 118:485-496.

42. Romer J, Nielsen BS, Ploug M: The urokinase receptor as a potential target in cancer therapy. Curr Pharm Des 2004, 10:2359-2376.

43. Mazar AP, Ahn RW, O'Halloran TV: Development of Novel Therapeutics Targeting the Urokinase Plasminogen Activator Receptor (UPAR) and Their Translation Toward the Clinic. Curr Pharm Des 2011.

44. Shimoda M, Mellody KT, Orimo A: Carcinoma-associated fibroblasts are a rate-limiting determinant for tumour progression. Semin Cell Dev Biol 2010, 21:19-25.

45. Cat B, Stuhlmann D, Steinbrenner H, Alili L, Holtkötter O, Sies H, Brenneisen P: Enhancement of tumor invasion depends on transdifferentiation of skin fibroblasts mediated by reactive oxygen species. J Cell Sci 2006, 119:2727-2738.

46. Magzoub M, Jin S, Verkman AS: Enhanced macromolecule diffusion deep in $t$ umors after enzymatic digestion of extracellular matrix collagen and its associated proteoglycan decorin. FASEB J 2008, 22:276-284.

47. Giannoni E, Bianchini F, Calorini L, Chiarugi P: Cancer associated fibroblasts exploit reactive oxygen species through a pro-inflammtory signature leading to EMT and stemness. Antioxid Redox Signal 2011.

48. Orimo A, Gupta PB, Sgroi DC, Arenzana-Seisdedos F, Delaunay T, Naeem R Carey VJ, Richardson AL, Weinberg RA: Stromal fibroblasts present in invasive human breast carcinomas promote tumor growth and angiogenesis through elevated SDF-1/CXCL12 secretion. Cell 2005, 121:335-348.

49. Eum SY, Lee YW, Hennig B, Toborek M: VEGF regulates PCB 104-mediated stimulation of permeability and transmigration of breast cancer cells in human microvascular endothelial cells. Exp Cell Res 2004, 296:231-244.

50. Ojalvo LS, Whittaker CA, Condeelis JS, Pollard JW: Gene expression analysis of macrophages that facilitate tumor invasion supports a role for Wntsignaling in mediating their activity in primary mammary tumors. $J$ Immunol 2010, 184:702-712.

51. Drabsch $Y$, ten Dijke P: TGF- $\beta$ signaling in breast cancer cell invasion and bone metastasis. J Mammary Gland Biol Neoplasia 2011, 16:97-108.

52. Truty MJ, Urrutia R: Basics of TGF-beta and pancreatic cancer. Pancreatology 2007, 7:423-435. 
53. Jones $S$, Zhang $X$, Parsons DW, Lin JC, Leary RJ, Angenendt $P$, Mankoo $P$, Carter $\mathrm{H}$, Kamiyama $\mathrm{H}$, Jimeno $\mathrm{A}$, et al: Core signaling pathways in human pancreatic cancers revealed by global genomic analyses. Science 2008, 321:1801-1806.

54. Ungefroren $H$, Sebens S, Groth S, Gieseler F, Fändrich F: Differential roles of Src in transforming growth factor- $\beta$ regulation of growth arrest, epithelial-to-mesenchymal transition and cell migration in pancreatic ductal adenocarcinoma cells. Int J Oncol 2011, 38:797-805.

55. Pandey J, Umphress SM, Kang Y, Angdisen J, Naumova A, Mercer KL, Jacks T, Jakowlew SB: Modulation of tumor induction and progression of oncogenic K-ras-positive tumors in the presence of TGF- $\beta 1$ haploinsufficiency. Carcinogenesis 2007, 28:2589-2596.

56. Ungefroren $H$, Groth $S$, Sebens $S$, Lehnert $H$, Gieseler F, Fändrich F: Differential roles of Smad2 and Smad3 in the regulation of TGF- $\beta 1$ mediated growth inhibition and cell migration in pancreatic adenocarcinoma cells: Control by Rac1. Mol Cancer 2011, 10:67.

57. Geismann C, Morscheck M, Koch D, Bergmann F, Ungefroren H, Arlt A, Tsao MS, Bachem MG, Altevogt P, Sipos B, Fölsch UR, Schäfer H, Müerköster SS: Up-regulation of L1CAM in pancreatic duct cells is transforming growth factor $\beta 1$ - and Slug-dependent: role in malignant transformation of pancreatic cancer. Cancer Res 2009, 69:4517-4526.

58. Ikushima H, Miyazono K: TGFbeta signalling: a complex web in cancer progression. Nat Rev Cancer 2010, 10:415-424.

59. Tan AR, Alexe G, Reiss M: Transforming growth factor-beta signaling: emerging stem cell target in metastatic breast cancer? Breast Cancer Res Treat 2009, 115:453-495.

60. Nagaraj NS, Datta PK: Targeting the transforming growth factor- $\beta$ signaling pathway in human cancer. Expert Opin Investig Drugs 2010, 19:77-91.

61. Ungefroren $H$, Sebens $S$, Groth S, Gieseler F, Fändrich F: The Src family kinase inhibitors PP2 and PP1 block TGF-beta1-mediated cellular responses by direct and differential inhibition of type I and type II TGFbeta receptors. Curr Cancer Drug Tar 2011, 11:524-535.

doi:10.1186/1478-811X-9-18

Cite this article as: Ungefroren et al:: Interaction of tumor cells with the microenvironment. Cell Communication and Signaling 2011 9:18.

\section{Submit your next manuscript to BioMed Central and take full advantage of:}

- Convenient online submission

- Thorough peer review

- No space constraints or color figure charges

- Immediate publication on acceptance

- Inclusion in PubMed, CAS, Scopus and Google Scholar

- Research which is freely available for redistribution

Submit your manuscript at www.biomedcentral.com/submit
Biomed Central 